\title{
Organoid Nevus
}

National Cancer Institute

\section{Source}

National Cancer Institute. Organoid Nevus. NCI Thesaurus. Code C4678.

A hamartomatous skin lesion containing sebaceous glands. It is usually located in the scalp. 